\title{
TopoNC: Essential First-Order Information
}

\author{
Jean Hiebert ${ }^{*}$
}

\author{
Patron:"I am looking for a globe of the earth." \\ Librarian: "We have a table-top model over here." \\ Patron: "No, that's not good enough. Don't you have a life-size?" \\ Librarian: (pause) "Yes, but it's in use right now." ${ }^{1}$
}

$I^{:}$ $\mathrm{n}$ a digital age, using paper maps may seem as absurd as asking for a life-sized globe. After all, GPS (global positioning systems) can tell us where to turn left, Google Earth can show exactly where the most recent bombings have occurred, and GIS (geographic information systems) can pinpoint the best market for a new coffee shop. Technology has converted maps, two-dimensional representations of three-dimensional objects, into geography complete with length, breadth, and depth. Before technology changed cartography, map users depended on the contour lines and shading of topographical maps to discern shape and elevation. Libraries that have collected print topographical maps for decades may now be facing the issues involved in replacing them with digital maps. Topographic maps occupy valuable space because of their size. They are subject to brittleness as they age. Their arrangement by quadrangle name is often confusing for patrons and librarians.

Despite all these seemingly valid reasons for discarding print topographic maps, they should remain in the collection for precisely the same justifications used to abandon them. Their size allows for small group use, their age lends a depth of knowledge concerning land form changes, and quadrangle names can be managed with a database. TopoNC (http://www.ecu.edu/cs-lib/ govdoc/GIS_Search.cfm) is offered by Joyner Library of East Carolina University (ECU) and it is the result of a collaborative effort by the library's maps and GIS coordinator and two of the library's Systems Department personnel. The goals were to produce a database that would assist both users and librarians in locating correct quadrangle maps with ease and to provide an electronic version of what had long been a paper-based inventory of local holdings.

Today most topographic maps can be viewed on computers and hand-held devices and, in some cases, cellular phones. It would be easy to assume from this that print sources are "redundant in favour of digital alternatives and that all of the intellectual products which we currently hold and that which would we like to hold, would be available in digital form either to acquire or to access." 2 Yet, most digital maps are adapted from print sources provided by the United States Geological Survey. Although the digital maps are useful, the benefits of print maps in certain situations outweigh the benefits of their electronic counterparts. For example, paper maps may have greater mobility, they are lighter and cheaper, and they are more user-friendly (the learning curve is minimal). The user may laminate a paper map, if needed, then simply roll it up and stash it with the hiking gear or slip it into a backpack when headed out for fieldwork. There is no need to worry about battery life, speed and reliability of the telecommunications connection, solar glare on a screen, resolution and contrast, accuracy of the information, or a screen size too small to capture all the data.

Topographic maps are framed by two longitude and two latitude lines of set value called quadrangles. The various scales for topographic maps include 1:24,000, 1:62,500, and 1:100,000. The state of North Carolina is divided into 953 quadrangles at the 1:24,000 scale and these maps are heavily used for both professional and recreational purposes. For librarians, organizing, finding, and disseminating these topographical maps can be problematic. Their sheer volume is just one part of the problem. The other is that each quadrangle (and therefore each topographic map) is usually named after a predominant town or feature. Libraries may choose to arrange the maps alphabetically by the quad names or catalog them by US Superintendent of Documents (SuDoc) classification number. Neither arrangement provides complete information on what features are part of each map. A patron seeking a topographic map for Raleigh Bay, for example, may have a general idea of its location in the state but have to sort through several maps of the area to find the one needed. A database that allows keyword searching could eliminate much of the guesswork.

For a better understanding of the importance of a searchable database such as TopoNC, a brief history of topographic maps and mapping in the United States is certainly useful. In a letter to the Continental Congress addressed to John Hancock, General George Washington, who was trained as a surveyor, wrote:

The want of accurate maps of the country which has been hitherto the scene of war has been of great disadvantage to me. I have in vain endeavoured to procure them, and have been obliged to make shift with such sketches as I could trace out from my observation and that of gentlemen around me... . ${ }^{3}$

In 1775 General George Washington appointed Robert Erskine as topographer for the Continental Army. ${ }^{4}$ Erskine and his staff issued more than 130 different maps between the time of his appointment and his death three years later. For the most part, the maps were first sketched upon a plane table in a roughly finished form. They delineated the roads and primary topographical features as well as commanding elevations and identification points such as the churches and taverns. ${ }^{5}$

Besides the obvious military importance of maps, the primary focus of mapping the land was to organize the country as a national unit and encourage the "settlement of the land, and the establishment of political divisions." The Continental Congress

* Science Reference Librarian, East Carolina University, Greenville, NC 
created the Geographer's Office in 1777 with the purpose of sketching the country, particularly the Philadelphia area since it served as the seat of war, but the Department was dissolved in 1783. After a thirty-year lapse, Congress in 1813 authorized the formation of the Topographical Bureau under the War Department Office. It held eight topographic engineers and eight associate topographic engineers. The task of the new Topographical Bureau was tremendous. A crude topographic map of the country was completed about forty years later in 1853 , but the project was far from inclusive and lacked cohesiveness. Individual map makers were allowed to design their own styles in the absence of standards for creating scales, symbols, or lettering. Even the prime meridian varied from map to map before the adoption of Greenwich, England, in 1874. Early American maps often depicted Washington, D.C. as the prime meridian.

After the Civil War, interest in the western section of the United States increased. Six hundred thousand square miles were mapped between 1867 and 1879 . What had heretofore been a predominantly military user group for topographical maps began to shift during this time; both the War Department and the Department of the Interior were conducting surveys with different aims. By 1878 it was clear that a central agency was needed. As a result, the United States
In a brochure produced by the United States Geological Survey, Theodore Steger defines a topographic map as "a line-and-symbol representation of natural and selected man-made features of a part of the Earth's surface plotted to a definite scale."10 The scale of $1: 24,000$ means that one inch on the map equals 2,000 feet on the ground. These rectangular quadrangles represent 7.5 meridians of longitude and 7.5 parallels of latitude, and are commonly referred to as quads. North Carolina is divided into 953 quads, each with a name that represents an outstanding feature of the area (fig. 1).

Much of the nomenclature for the quads is based primarily on local usage. ${ }^{11}$ In cases of dispute, the issues are resolved by the Board on Geographic Names, established in 1890 by President Benjamin Harrison. The Board works closely with "State geographic name authorities, State and local governments, and the general public in order to determine the choice, spelling, written form, and applications of each name for official use."12

North Carolina has many interesting and unusual place names that have become quad names. For example, Alarka, a small community in Swain County serves as the quad name for the area because it is the most prominent town. A library patron wanting a topographical map of the Alarka quad may choose to view it on

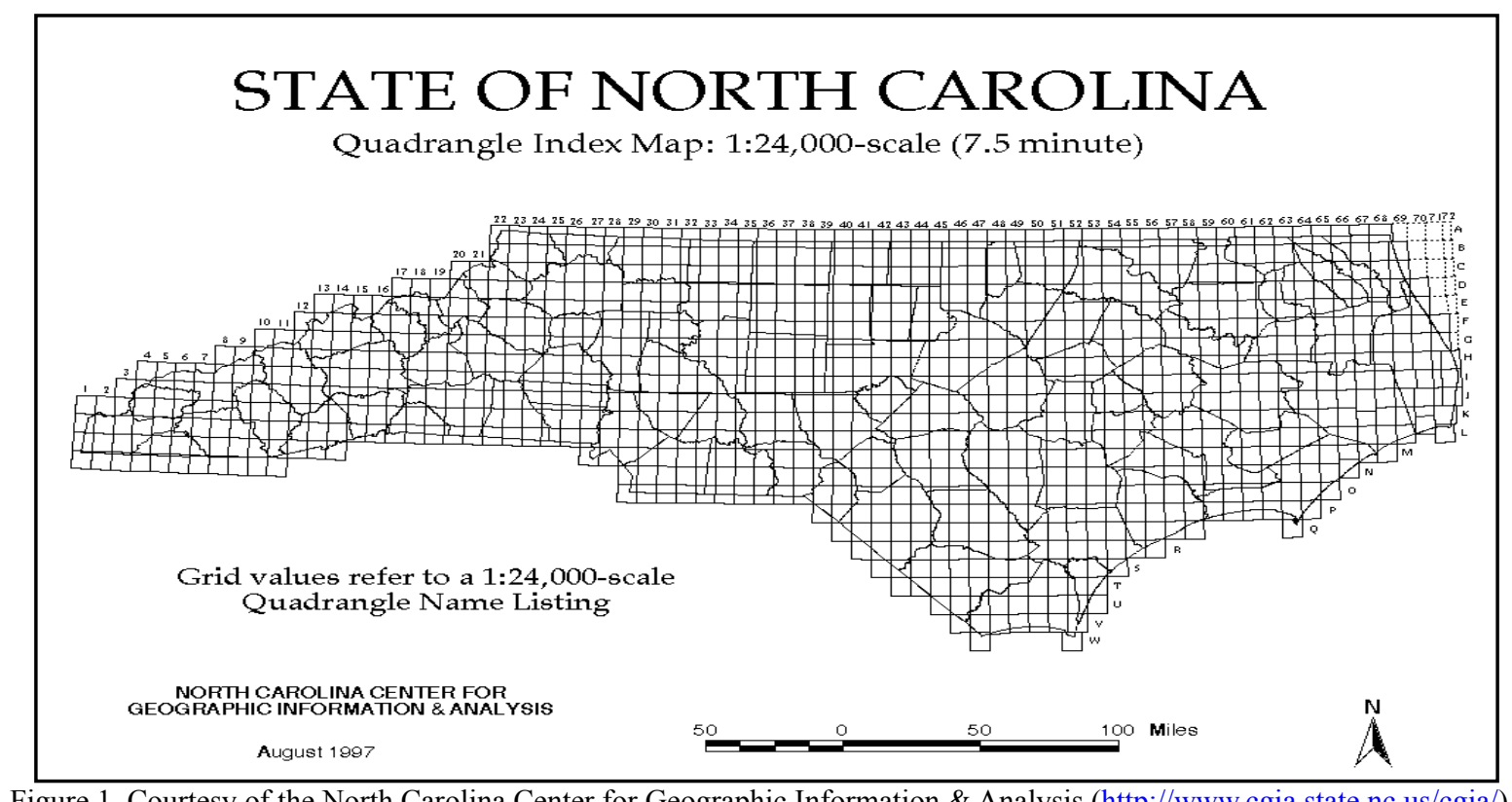

Figure 1. Courtesy of the North Carolina Center for Geographic Information \& Analysis (http://www.cgia.state.nc.us/cgia/)

Geological Society was created on March 3, 1879. John Wesley Powell, the first regular director of the USGS, created a plan for topographic mapping of the nation in 1882. Powell created the quadrangle divisions and set different scales for different regions: $1: 250,000$ for underdeveloped areas in the west, 1:125,000 in the east, and 1:62,500 for areas of heavy cultural development in the east. ${ }^{7}$ The 1:24,000 scale, implemented in the early twentieth century, eventually became the standard. The quadrangle division allows systematic control of maps sheets, providing a method for measurement in meridians and parallels so that adjacent areas are uniform. ${ }^{8}$ The maps have been updated continuously, with the most recent revisions completed in 2005 . They have served as the "standard for accurate, detailed land cover information on which many digital sources are based.",
Topozone (http://www.topozone.com) a free Website, or see the map as a digital raster graphic through the GNIS website. Perhaps the patron has access to a digital state atlas furnished by DeLorme (http://www.delorme.com) that provides maps at a relatively low cost with finer resolution than digital raster graphics that are generally scanned at 250 dots per inch. Regardless of how the topographical map for Alarka is accessed, the patron who wishes to take it into the field must either download it to a portable form such as a laptop, a palm pilot, or a cell phone, or must make a paper copy of it. The difficulties of using portable technologies in fieldwork have previously been addressed and making paper copies of maps at the correct scale and size requires access to expensive copiers/printers (approximately $\$ 10,000$ ). 
Print topographical maps for Alarka are available at Joyner Library for the years 1940 and 1981, allowing comparisons of land forms over time. Geographers McChesney and McSweeney use print topographic maps in university classrooms precisely because they allow the study of land form changes over time, often at depths of four to five decades for a set of maps. ${ }^{13}$ These maps also possess unusually standardized formats and are widely available, free of charge, in university libraries. In fact, the 7.5 topographic maps for the state of North Carolina are the most heavily used of all the maps collections at Joyner Library. Those housed in the Government Documents Department circulate to both ECU affiliates and non-affiliates, while those in the North Carolina Collection do not circulate.

The most common use for topographic maps at East Carolina University appears to be for fieldwork by professors and students in Geology, Biology, and Geography. Besides being highly mobile, print maps are easier for groups to use. Dr. Mark Brinson, a professor of Biology and Coastal Resources Management at ECU, noted that "laptops in the field are fairly useless because you can't see the screen, they are bulky, etc. Nothing like a folded-up map for the field." ${ }^{14}$ Dr. L.J. Palmer-Maloney of ECU's Geography Department commented that

\begin{abstract}
When working in the field, the print 7.5 topo maps are critical to have. They do not have to hope they printed out the right part of the topo from the computer image; they can actually READ information from the USGS print topos (which is NOT always the case with those they have to print from the computer--unless GOOD QUALITY / nearly photo quality paper and COLOR ink are available for them to use to print!). As a professor who has taken small classes of students in the field, it is important to me that the maps we are using be readable and reliable. USGS 7.5 minute topos have always worked--ESPECIALLY in field setting where getting on a computer is NOT an option. ${ }^{15}$
\end{abstract}

Computers may not yet be feasible in the field, but Dr. David Lawrence of ECU's Geology Department predicted that in the future "possibly everyone will have topography on GPS units or portable computers instead, but we are not there yet. Paper copies are still useful." 16 So useful, in fact, that Dr. Catherine Rigsby commented that their use is taught in all introductory geology labs. ${ }^{17}$ Digital maps provided by TerraServer are useful for projecting onto a large screen for group discussion, but require an internet connection and an LCD projector. Dr. Joe Luczkovich has used this method, but added that they always take paper maps into the field because they require almost no setup. ${ }^{18}$

Once in the field, geology students and professors use the topographical maps for "locating sample sites, geologic mapping, exploring geomorphic features, studying stream flow, delineating drainage basins, investigating landslide potential, recognizing old beach ridges, etc." ${ }^{19}$ Biology students and professors may use them to find "sampling sites for headwater streams, topographic information for wetlands, and just reading the landscape."20

Getting the right map to take into the field can be a challenge for both librarian and user. At Joyner, not all of the topographic maps are yet cataloged. Both the Government Documents Department and the North Carolina Collection have been relying on paper indexes to inventory their holdings, but paper indexes are no longer considered efficient or effective means for acquisitions, cataloging, bibliographic instruction or outreach purposes "because manual indexes are very time-consuming to fill in [and] open-stack collections often keep manual indexes heavily guarded in the workroom." 21 The Cataloging Department at Joyner is currently inundated with the work of cataloging electronic resources. Topographic maps, out of necessity, have been placed on a back burner.

Searching the library's catalog for print holdings of cataloged maps can be an exercise in frustration for a novice user, and reference librarians are stymied when patrons request material without complete information. A search using the appropriate Library of Congress subject heading "North Carolina-Maps, Topographic" results in holdings for all of the scales for state topographic maps unless a particular quad name is already known. Some universities have simplified the process by creating special databases for locating maps within the library. The Data, Government and Geographic Information Services at the University of California at San Diego, for example, uses Map Finder for locating map series. A Web site (http://govinfo.ucsd.edu/maps/howto.html) gives step-by-step instructions on finding maps, but cautions that this tool works best when coordinates of latitude and longitude are entered-something that students may not know.

Owen Science and Engineering Library at Washington State University offers its Inventory of U.S. Geological Survey Topographical Maps (http://www.systems.wsu.edu/maps/) that requires the user to enter both the state name and the quad name. Directly beneath the search box is a "WARNING!!!" that failing to enter a quad name will retrieve all the quads for a state. To find a quad name, the Web site directs users to the Geographic Names Information System. Once in the GNIS database, the user must launch an advanced search and advance through several screens to find the quad name.

Yale's Peabody Museum GNIS database (http://research.yale. edu/peabody/COLLECTIONS/gnis) offers greater precision searching. Users submit a city or town, select a state from a list, then select a particular feature (single) or any feature (multiple). The user may then limit by a county name, if known. The records that are retrieved include the feature name, the feature type, the county, the coordinates, and the map name (quad name). The database includes all 50 states and is more intuitive than the federal government's GNIS database.

At Joyner Library, a growing need for an electronic inventory of topographical map holdings and a method for quickly finding a correct quad name to improve client service led to the creation of TopoNC, a database that allows searching by keyword and that retrieves the county name, quad name, latitude, longitude, print holdings, and digital raster graphics from the TerraServer.

The first step in creating the database was to inventory the print 7.5 topographical maps in both the Government Documents Department and the North Carolina Collection. While the inventory was conducted, the library's Systems personnel downloaded the data regarding the 7.5 topographic maps for North Carolina from the Geographic Names Information System Website. The data is 
made available in comma-delimited text files that were broken into tables before being moved to the newly created database. No changes were made to any names or feature types therefore quad names are represented in the database by various feature types such as populated place, bay, swmp, etc.

ColdFusion serves as the web interface and the database resides on the Common Spot web server. To add the TerraServer maps, Systems personnel retrieved the longitude, latitude, northing, and easting information for each quad from the USGS. The following parameters were used to obtain the TerraServer maps that matched the directional information from the USGS (fig. 2):

\begin{tabular}{|ll|}
\hline Easting $/ 3200=\mathrm{x}$ & 16 meters per screen dot \\
Northing $/ 3200=\mathrm{y}$ & Zone 17 for North Carolina \\
Scale $=14$ & $\mathrm{~T}=2$ for the topographic map \\
\hline
\end{tabular}

Figure 2

The basic TopoNC search screen allows the user to search by keyword, county, feature name, feature type, or quad name (fig. 3).

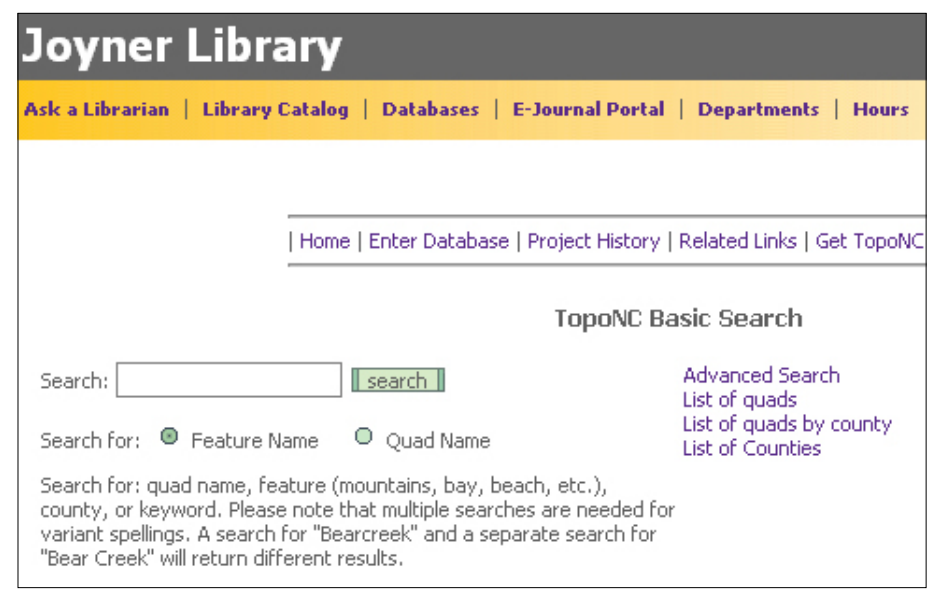

Figure 3

Simple instructions below the search box address the problem of spelling variations. Hyperlinked lists for quad names, quad names by county, and county names provide additional information to facilitate the search process.

Abasic search of the quad "Abbottsburg" returns a series of screens, the first of which shows the keyword as entered and the feature type (fig. 4). Clicking on the hyperlinked term "Abbottsburg" retrieves the county name, the quad name, the latitude and longitude coordinates, and a hyperlink for Joyner Library's print holdings (fig. 5). The final screen provides the print holdings and a map of the quad from the TerraServer. (fig. 6)

\section{Joyner Library}

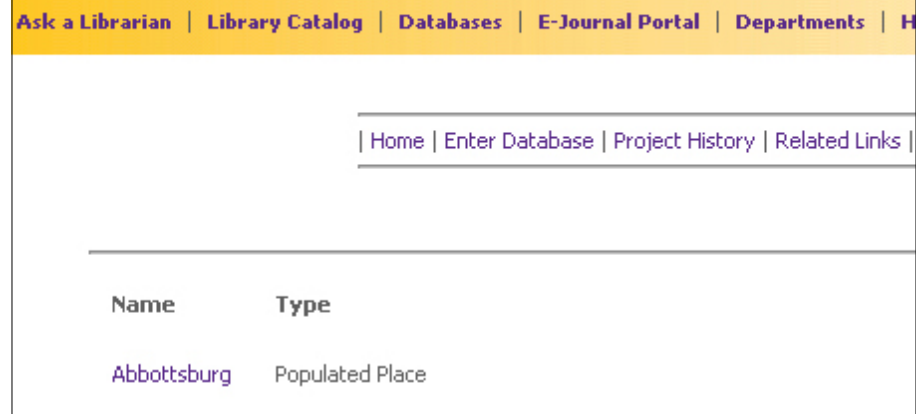

An advanced search feature Fildwe the user to search a feature name or quad name by keyword then limit by county name or

\begin{tabular}{|c|c|c|c|}
\hline \multicolumn{4}{|c|}{ Joyner Library } \\
\hline \multicolumn{4}{|c|}{ 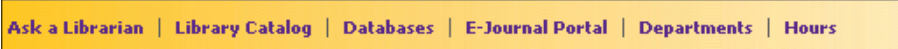 } \\
\hline & \multicolumn{3}{|c|}{ | Home | Enter Database | Project History | Related Links | Get TopoNC @ } \\
\hline \multicolumn{4}{|c|}{ Abbottsburg -- Populated Place } \\
\hline County & Quad & Latitude & Longitude \\
\hline Eladen & Abbottsburg & $343101 \mathrm{~N}$ & $0784331 w$ \\
\hline
\end{tabular}

feature type (fig 7).

Figure 5

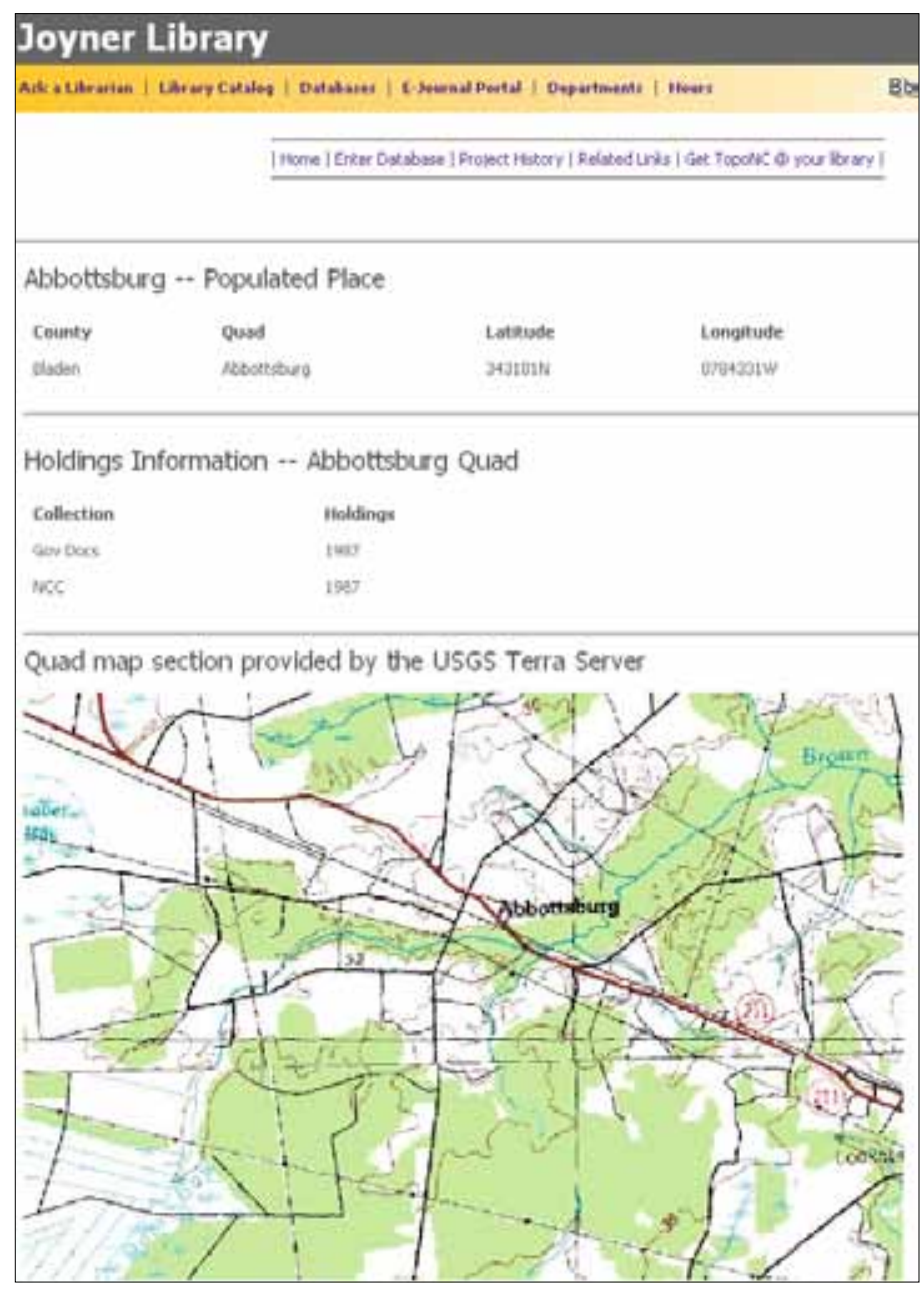

Figure 6 
An introductory page to the database explains some of the peculiarities of the topographical information, such as the inconsistent definitions for feature names. The GNIS Board website offers the following explanation for the variations in Joyner Library

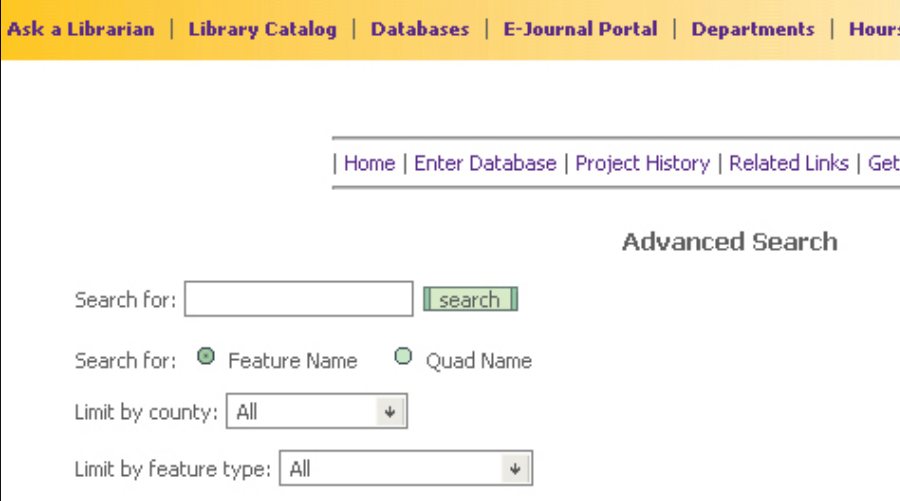

feature names: "There are no official definitions for generic terms as applied to geographic names. Every organization will have a definition that is application driven, and no one office definition is accepted as official. The difference is thematic and beyond that it is highly perceptive." It would seem that a lake by any other name could be a creek, or a river, or a pond, or maybe just a lake. The data for feature names and types was downloaded into TopoNC with no changes to the designations given to place or type.

Joyner Library is currently exploring the purchase of a map copier/ printer and has plans to apply for grant funding to digitize the collection of 7.5 topographic maps. Fieldwork requires disposable maps that can get dirty, wet, marked up, or even folded up (despite our encouragement to use map tubes). The use of disposable maps would help to protect our collection of 7.5 maps, some of which date to the 1930s. With digitized maps and a map printer/copier, students could produce their own map(s) at minimal cost. The resolution of our digitized maps would be finer than that currently offered by the TerraServer currently offers. The digitized maps would also be of use to our growing distance education population. Faculty in Biology, Geology, and Geography who offer online courses would have access to high-resolution digitized maps with the temporal depth necessary to demonstrate landform changes.

Freely available 7.5 topographic maps provide essential first-order information for faculty, researchers, and students, particularly in areas such as history, geography, geology, coastal management, and planning. TopoNC allows for greater access to these maps by overcoming the issue of quad names. Mark Brinson of ECU's Biology Department agrees and further comments that "It is a great convenience to be able to know at the click of the mouse what maps are available in both Government Documents and the North Carolina Collection. This service saves a lot of time by eliminating the effort needed to track them down, minimizes the uncertainty of what is readily available, and reduces the cost of ordering them from the NC Geological Survey." 22

As an easily searchable database, it provides a key electronic inventory of print 7.5 topographic maps that restores valuable historical information lost by keeping a paper inventory. Dr. Tom Crawford, an assistant professor new to the department of Geography, enthusiastically supports TopoNC as an easily searchable tool and comments that "This project demonstrates institutional commitment towards allocation of resources for documenting and disseminating geographic information. Given the tremendous increase in geospatial technologies and data, this is a wise resource allocation that probably should be continued and even increased in the future. The project creator(s) is to be highly commended for make this resource available to the campus community." ${ }^{23}$

Plans for modifications to the database include the addition of topographic maps for the state drawn at other scales, such as the 1:62,500 maps. County names will be hyperlinked in order to point the user to valuable information such as census data, local government websites, and education institutions. Quad names will be hyperlinked so that users may access historical information about the quads.

TopoNC is freely available on the Joyner Library website (http:// www.ecu.edu/lib/). Libraries with collections of 7.5 topographical maps for North Carolina may find it useful for locating particular quads. Celia Pratt, a reference and maps librarian at the University of North Carolina at Chapel Hill, commented that librarians at Davis Library are using a gazetteer to chart their holdings for print topographic maps. ${ }^{24}$ TopoNC can be adapted to reflect map holdings for other libraries and, as for Davis Library, provide an alternative to paper inventories. After reviewing the database, Ms. Pratt endorsed it as a great tool for answering map reference questions and remarked that "I appreciate that it's possible for others to download and customize." ${ }^{25}$ The introductory page to the database includes a link to source information for those who would like to avoid recreating the wheel. Anyone may copy it without securing permission from Joyner Library. Included are instructions on how to add individual local holdings. It will be necessary to download local print holdings to the SQL database and add identification numbers for each quad map and each local holding. Some adjustments must be made to fit the information into the structure of the database. It will also be necessary to establish a system to add future acquisitions to the database. At Joyner, the maps librarian alerts the Systems Department to the acquisition of a map. They capture any new information from GNIS and TerraServer or add the new holding to an already existing record. Armed with information from the North Carolina Geological Survey, 100 maps were recently ordered to complement the existing collection. TopoNC made it easy to determine which maps should be ordered from the long list of topopgrahical maps published between 1999 and 2005.

What began as a method for inventorying Joyner's collection of topographic maps quickly progressed to the development of a tool that has multiple uses. Libraries, government offices, and corporations are invited to customize TopoNC to reflect their own collections of topographic maps and to share any new ways to use the database that they discover in the process.

\section{References}

1"Overdue Laughs," http://www.librarysupportstaff.com/ libhumor.html (May 10, 2006).

${ }^{2}$ J.P. McCarthy, "Digital Knowledge vs Print Preservation: Future 
Possibilities for remote storage." http://www.iuisc.ie/2001/ presentations/jpmcarthy.htm (April 30, 2006).

${ }^{3}$ Silvio A.Bedini, "The History Corner: Robert Erskine (17351780) Geographer and Survey-General of the Continental Army, Part 1," Professional Surveyor 22, no. 3 (2002). http://www. profsurv.com/archive.php?issue=62\&article=872 (May 1, 2006).

${ }^{4}$ Mary Lynette Larsgaard, Topographic Mapping of the Americas, Australia, and New Zealand (Littleton, Colo:Libraries Unlimited, 1984), 92.

${ }^{5}$ Silvio A.Bedini, “The History Corner: Robert Erskine (17351789) Geographer and Surveyor-General of the Continental Army, Pt. II" Professional Surveyor 22, no. 4 (2002), http:// www.profsurv.com/archive.php?issue $=63 \&$ article $=887$ (May 10, 2006).

${ }^{6}$ F. J. Marschner, "Maps and a Mapping Program for the United States" Annals of the Association of American Geographers 33, no. 4 (1943), 199.

${ }^{7}$ Larsgaard, 94.

${ }^{8}$ Malcolm P. Weiss, Topographic Maps and How to Use Them (Englewood Cliffs, N.J.: Prentice-Hall, 1965), 6.

${ }^{9}$ Ron McChesney and Kendra McSweeney, "Topographic Maps: Rediscovering an Accessible Data Source for Land Cover Change Research," Journal of Geography 104 (2005), 161.

${ }^{10}$ U.S. Department of the Interior, Geological Survey, Topographic Maps, by Theodore Steger, (Washington, D.C.: Government Printing Office, 1976). 3.

${ }^{11}$ Ibid, 22.

${ }^{12}$ Donald J. Orth and Roger L. Payne, "Principles, Policies, and Procedures: Domestic Geographic Names," online ed. rev. (Geographic Names Information System, United States Geological Society, 2003), http://geonames.usgs.gov/pppdgn. html\#CH1 (June 15, 2006).

${ }^{13}$ McChesney and McSweeny, 162.

${ }^{14}$ Mark Brinson, Personal communication, May 10, 2006.

${ }^{15}$ L.J. Palmer-Maloney, Personal communication, May 3, 2006.

${ }^{16}$ David Lawrence, Personal communication, May 11, 2006.

${ }^{17}$ Catherine Rigsby, Personal communication, May 15, 2006.

${ }^{18}$ Joe Luczkovich, Personal communication, May 16, 2006.

${ }^{19}$ Teri Woods, Personal communication, May 19, 2006.

${ }^{20}$ Mark Brinson, Personal communication, May 10, 2006.

${ }^{21}$ Mary Lynnette Larsgaard, Map Librarianship An Introduction, $3^{\text {rd }}$ ed. (Englewood, Colo.: Libraries Unlimited, 1998), 13.

${ }^{22}$ Celia Pratt, Personal communication, June 30, 2006.

${ }^{23}$ Mark Brinson, Personal communication, November 7, 2006.

${ }^{24}$ Tom Crawford, Personal communication, November 15, 2006.

${ }^{25}$ Celia Pratt, Personal communication, August 25, 2006. www.profsurv.com/archive.php?issue $=62$ \&article $=872$ (May 1, 2006).

"The History Corner: Robert Erskine (1735-1789) Geographer and Survey0r-General of the Continental Army, Pt. II." Professional Surveyor 22, no.4 (2002), http:/www.profsurv.com/archive. php?issue $=63 \&$ article $=887$ (May 10, 2006).

Larsgaard, Mary Lynnette. Map Librarianship An Introduction $3^{\text {rd }}$ ed. Englewood, Colo.:Libraries Unlimited, 1998.

Topographic Mapping of the Americas, Australia, and New Zealand. Littleton, Colo.: Libraries Unlimited, 1984.

McCarthy, JP. Digital Knowledge vs Print Preservation: Future possibilities for remote storage. http://www.iuisc.ie/2001/ presentations/jpmcarthy.htm (April 30, 2006).

McChesney, Ron and Kendra McSweeney. "Topographic Maps: Rediscovering an Accessible Data Source for Land Cover Change Research.” Journal of Geography 104 (2005): 161-178.

Marschner, F.J. "Maps and a Mapping Program for the United States." Annals of the Association of American Geographers 33, no. 4 (1943): 199-219.

Orth, Donald J. and Roger L. Payne. "Principles, Policies, and Procedures: Domestic Geographic Names," Geographic Names Information System, United States Geological Society, 2003. http://geonames.usgs.gov/pppdgn.html\#CH1, June 15, 2006.

“Overdue Laughs" http://www.librarysupportstaff.com/libhumor. html (May 10, 2006).

U. S. Department of the Interior. Geological.Survey. Topographic Maps, by Theodore Steger. Washington, D.C. Government Printing Office, 1976.

Weiss, Malcolm P. Topographic Maps and How to Use Them Englewood Cliffs, N.J.Prentice-Hall, 1965.

\section{Selected Bibliography}

Bedini, Silvio A. "The History Corner: Robert Erskine (17351780) Geographer and Surveyor-General of the Continental Army, Part 1.” Professional Surveyor 22, no. 3 (2002). http:// 